\title{
Evaluation of an almond collection using morphological variables to choose superior trees
}

\author{
Erfan Sepahvand $^{1}$, Abdollah Khadivi-Khub ${ }^{2 \star}$, Ali Momenpour ${ }^{1}$ and Esmaeil Fallahi ${ }^{3}$ \\ 1 Department of Horticultural Sciences, Faculty of Agriculture, University of Tehran, 31587 Karaj, Iran \\ 2 Department of Horticultural Sciences, Faculty of Agriculture and Natural Resources, Arak University, 38156-8-8349 Arak, Iran \\ 3 Department of Plant, Soil and Entomological Sciences, University of Idaho, Parma Research and Extension Center, Parma, Idaho 83660, \\ USA
}

Received 3 September 2014 - Accepted 15 November 2014

\begin{abstract}
Introduction. Iranian almond germplasm is regarded as one of the most diverse and valuable genetics resources for almond improvement. Materials and methods. In the present study, 155 almond genotypes were evaluated to determine the overall degree of variation and to detect superior trees. The variation was observed for traits related to phenology, morphology, yield and fruit quality. Results and discussion. Nut and kernel traits contributed most of the total variation but there were also significant differences in flowering and ripening times. The majority of important correlations were determined between the characteristics representing nut size and kernel size. Cluster and principal component analyses confirmed considerable diversity in the studied germplasm. Conclusion. Genotypes MSh11, MSh100, MSh97, MSh24 and MSh126 were the best trees in terms of flowering season, consistently high fruit set, large nut and kernel size, and low percentage of double kernels. Furthermore, genotypes MSh9 and MSh110 were very late flowering and could be useful in breeding to improve flowering season of almond.
\end{abstract}

Keywords: Iran / Prunus dulcis / almond / indigenous cultivars / flowering / fruit set

Résumé - Evaluation d'une collection d'amandiers pour choisir des individus élites d'après des critères morphologiques. Introduction. L'iranien est considéré comme l'une des sources de matériel génétique les plus diverses et utiles pour l'amélioration de l'amandier. Matériel et méthodes. Dans la présente étude, 155 génotypes d'amandier ont été évalués pour déterminer le degré de variabilité globale et détecter les arbres élites. La variabilité a été observée pour les caractères liés à la phénologie, la morphologie, au rendement et à la qualité des fruits. Résultats et discussion Les caractères liés à l'amande et à son noyau ont contribué le plus à la variabilité totale. En outre, les génotypes étudiés ont présenté des différences importantes de dates de floraison et de maturation des fruits. La plupart des corrélations significatives ont été déterminées entre les caractéristiques liées à la taille de l'amande et celles liées à la taille du noyau. L'analyse par cluster et l'analyse en composantes principales ont montré une grande diversité dans le matériel génétique étudié. Conclusion. Les génotypes MSh11, MSh100, MSh97, MSh24 et MSh126 se sont montrés les meilleurs amandiers en termes de mise à fruits régulière et productive, dont les critères culturaux de gros fruits à gros noyaux, de saisons de floraison régulières et de faible pourcentage de noyau double peuvent être distingués. De plus, les génotypes MSh9 et MSh110 se sont révélés de floraison très tardive ce qui valoriserait ces géniteurs en croisement pour produire une population particulièrement adaptée ou pour améliorer la période de floraison de certains cultivars.

Mots clés : Iran / Prunus dulcis / amandier / cultivars locaux / floraison / mise à fruit

\section{Introduction}

Almond (Prunus dulcis L.) is one of the most important nut crops in the world [1]. The marketed product is the edible seed (the kernel), which is used for direct consumption and for baked products and confections [1,2]. The cultivated almond was probably domesticated during the $3^{\text {rd }}$ millennium BC. Two

\footnotetext{
* Corresponding author:

akhadivi@ut.ac.ir, a-khadivi@araku.ac.ir
}

ecotypes have evolved over time: Mediterranean and Central Asian $[3,4]$. Numerous related wild species are also found growing in the mountains and deserts of Central Asia from western China through Iran and Turkey [1]. These native almond species are utilized for oil extraction, soil erosion control, reforestation, rootstocks, and as a source of novel genes in breeding programs [5].

Local and foreign cultivars and clones are grown in Iran and, because of almond short juvenile phase, sexual 
propagation is still being used by local growers. Accurate characterization of almond seedling cultivars and rootstocks is essential for the identification of clones that will guarantee uniformity [6] of commercial orchards.

Morphological characterization of germplasm collections is the reference for plant breeders wishing to utilize the germplasm in their programs. Characterization of morphological traits is also essential to document and study the genetic diversity within the collection, which can facilitate the establishment of core collections that fully represent the diversity of the collection $[7,8]$.

Revealing the genetic diversity of germplasm collections has mainly been based on traditional multivariate statistical analyses, such as hierarchical cluster analysis, principal component analysis, and multidimensional scaling, usually using horticultural or agronomic data [9]. As a place of origin of the almond, the genetic diversity of almond germplasm in Iran has been widely investigated by the use of hierarchical and principal component analyses [10-12]. Iranian almond germplasm is regarded as one of the most diverse and valuable of almond genetic resources in the world.

In this study, we evaluated 155 genotypes over two consecutive years with the objectives of: 1) evaluating the phenotypic variation of 42 interesting horticultural and morphological traits and their relationships; 2) studying the extent of morphological variation amongst the studied germplasm; and 3) selection of superior genotypes of interest to moderate vigour, flowering time (extension of the blooming season) and improve kernel yield (both quantity and quality).

\section{Materials and methods}

\subsection{Plant materials}

A total of 155 almond accessions from a collection in Karaj, Iran were evaluated over two seasons. Karaj city is located in Alborz province, at $35^{\circ} 56^{\prime} 30^{\prime \prime} \mathrm{N}$ latitude, $50^{\circ} 58^{\prime} 10^{\prime \prime} \mathrm{E}$ longitude and $1312 \mathrm{~m}$ above the sea level with an annual average temperature of $13.8^{\circ} \mathrm{C}$ and an annual average precipitation of $260 \mathrm{~mm}$. General orchard management, including irrigation, nutrition, pest and disease control, was consistent with local commercial practices. At the beginning of the study (2010), the trees were eight years old, healthy, and had a full crop.

\subsection{Morphological evaluation}

During two growing seasons, 42 morphological characters were studied using the almond descriptors developed by the International Plant Genetic Resources Institute (IPGRI) [13] (table I). Measurement of each nut and kernel trait was based on the mean value of 10 samples. Weight of fruits, nuts and kernels was measured by an analytical balance with high precision $(0.01 \mathrm{~g})$. Traits such as tree growing habit, tree vigour, leaf density, fruit shape, kernel color and kernel taste were rated and coded according to the IPGRI almond descriptor. Horticultural traits evaluated included flowering date (50\% flowers completely open evaluated from March to April and classed as relatively early, normal, late and very late within this period) and ripening date (evaluated from end of July to end of September and classed as early, middle, late and very late within this period). Five cultivars including Mamayi, Sefid, Azar, Shahrood12 and Tardy-Nonpareil were used as controls for checking flowering time.

For those traits that can be affected by environmental conditions from year to year, the data resulting from the twoyear study were pooled and the average values were used for statistical analysis. Analysis of variance was performed for all morphological traits by SAS software version 6. Relationships among genotypes were investigated by multivariate analysis of variance (principal component analysis, PCA) using SPSS statistics software version 16 (SPSS Inc., Chicago, IL, USA). The correlation between all variables was also evaluated using Pearson's correlation coefficient using SPSS. Euclidean distance coefficient for pairs of entries (i.e. genotypes) was computed using NTSYSY-pc (Numerical Taxonomy and Multivariate Analysis for personal computer) software program version 2.00. To better understand the patterns of variation among genotypes, distance matrix generated from morphological data was used as input data for cluster analysis based on unweighted pair-group method of arithmetic average (UPGMA). Scatter plot of the first two principal components was created by PAST statistics software [14].

\section{Results and discussion}

The analysis of variance revealed that all traits showed large differences, indicating a high level of morphological variation in the 155 genotypes. Therefore, this variability can be used either in cultivar selection for orchards or parent in breeding programs. This was confirmed by the relatively high coefficient of variation (CV) values established for traits. Among the measured traits, the highest levels of variation were found for ease of hulling $(\mathrm{CV}=89.7 \%)$ while fruit pubescence showed the lowest differences $(\mathrm{CV}=15.9 \%)$ among the genotypes. This degree of variability is similar to that found by Zeinalabedini et al. [11] who reported a range of 5.9 to $76.1 \%$ for $\mathrm{CV}$ for morphological traits in almond germplasm. In our study, we found good genotype candidates for extending the blooming season, moderating vigour and improving fruit quality.

The majority of the genotypes were characterized by a spreading growth habit and strong tree vigour, in agreement with findings of Zeinalabedini et al. [11] and Colic et al. [15]. Leaf density of most of the genotypes was high. Results of the full bloom date assessment showed that these genotypes had significant differences in bloom date, ranging from March 16 to April 9, showing six groups based on flowering date including early, middle, middle-late, late, late to very late and very late within this period. In comparison to the control cultivars, most of genotypes were middle-late flowering. Genotype MSh85 was the earliest to bloom, flowering in middle March and likely having the lowest chilling requirements among the studied genotypes. The latest genotype to bloom was MSh110, flowering on April 9. Also, genotype MSh9 was late to very late flowering. Given that frost resistance is a major breeding goal in many production areas owing to cultivated almond very early flowering time. The possibility of using these genotypes (MSh110 and MSh9) with a late to very late flowering date as 
Table I. Descriptive statistics for morphological characters among the studied almonds. CV: coefficient of variation $=($ standard deviation/mean) $\times 100$.

\begin{tabular}{|c|c|c|c|c|c|c|}
\hline No. & Trait & Abbr. & Unit & Min. & Max. & Mean \\
\hline 1 & Fruit weight & FrWe & g & 4.36 & 23.81 & 9.44 \\
\hline 2 & Nut weight & NuWe & $\mathrm{g}$ & 1.28 & 9.23 & 2.96 \\
\hline 3 & Kernel weight & KeWe & g & 0.46 & 2.28 & 1.12 \\
\hline 4 & Nut weight/Fruit weight & $\mathrm{Nu} / \mathrm{FrWe}$ & Ratio & 0.14 & 0.53 & 0.32 \\
\hline 5 & Kernel weight/Nut weight & $\mathrm{Ke} / \mathrm{NuWe}$ & Ratio & 0.19 & 0.97 & 0.42 \\
\hline 6 & Kernel weight/Fruit weight & $\mathrm{Ke} / \mathrm{FrWe}$ & Ratio & 0.05 & 0.26 & 0.12 \\
\hline 7 & Fruit density & FrDe & Code & 1 & 9 & 4.61 \\
\hline 8 & Fruit size & $\mathrm{FrSi}$ & Code & 1 & 9 & 5.66 \\
\hline 9 & Fruit shape & FrSh & Code & 1 & 7 & 4.50 \\
\hline 10 & Fruit pubescence & $\mathrm{FrPu}$ & Code & 3 & 7 & 6.26 \\
\hline 11 & Kernel pubescence & $\mathrm{KePu}$ & Code & 1 & 7 & 2.26 \\
\hline 12 & Kernel shriveling & $\mathrm{KeS}$ & Code & 1 & 7 & 3.50 \\
\hline 13 & Double kernels & DoKe & Code & 1 & 9 & 1.05 \\
\hline 14 & Kernel taste & $\mathrm{KeTa}$ & Code & 3 & 7 & 3.95 \\
\hline 15 & Shape of nut tip & ShNuTi & Code & 1 & 5 & 3.27 \\
\hline 16 & Marking of outer shell & MaOShe & Code & 3 & 9 & 5.25 \\
\hline 17 & Suture opening of the shell & SOSh & Code & 1 & 9 & 2.96 \\
\hline 18 & Ease of hulling & $\mathrm{EHu}$ & Code & 1 & 9 & 3.34 \\
\hline 19 & Nut Shape & $\mathrm{NuSh}$ & Code & 1 & 9 & 5.99 \\
\hline 20 & Nut size & $\mathrm{NuSi}$ & Code & 1 & 9 & 4.75 \\
\hline 21 & Shell hardness & SheHa & Code & 1 & 9 & 5.13 \\
\hline 22 & Shell color intensity & ShCoI & Code & 1 & 7 & 4.71 \\
\hline 23 & Kernel size & $\mathrm{KeSi}$ & Code & 1 & 9 & 4.87 \\
\hline 24 & Kernel color intensity & $\mathrm{KeCoI}$ & Code & 1 & 9 & 4.15 \\
\hline 25 & Canopy diameter & $\mathrm{CaDi}$ & Code & 1 & 9 & 6.12 \\
\hline 26 & Tree height & TrHe & Code & 1 & 9 & 5.79 \\
\hline 27 & Tree vigour & TrVi & Code & 3 & 7 & 5.94 \\
\hline 28 & Tree growth habit & TrGHab & Code & 1 & 9 & 5.19 \\
\hline 29 & Tree habit of branches & TrHB & Code & 3 & 9 & 6.61 \\
\hline 30 & Leaf density & LDe & Code & 3 & 7 & 6.34 \\
\hline 31 & Current year old shoot color & CYOlShoCo & Code & 3 & 9 & 5.36 \\
\hline 32 & One-year old shoot thickness & OnYOlShTh & Code & 3 & 7 & 5.45 \\
\hline 33 & Leaf blade color & LBCo & Code & 3 & 7 & 4.48 \\
\hline 34 & Leaf serration shape & LSerSh & Code & 1 & 5 & 2.00 \\
\hline 35 & Blooming density & $\mathrm{BlD}$ & Code & 1 & 9 & 7.29 \\
\hline 36 & Double flower percentage in buds & DoFlo & Code & 1 & 7 & 3.17 \\
\hline 37 & Pistil number & PiNo & Code & 1 & 5 & 1.84 \\
\hline 38 & Petal color & PetCo & Code & 1 & 7 & 2.88 \\
\hline 39 & Location of flower buds & LoFloBu & Code & 1 & 5 & 3.86 \\
\hline 40 & Position of stigma compared to anther & PSt & Code & 1 & 5 & 3.21 \\
\hline 41 & Flowering data & FloDa & Day & 16-Mar & 09-Apr & - \\
\hline 42 & Ripening date & RiDa & Day & Late-July & Late-Sep & - \\
\hline
\end{tabular}

commercial cultivars or to develop new cultivars with delayed flowering would not only reduce frost damage, but reduce disease damage if flowering was delayed beyond the rainy season. It would also allow more efficient use of increasingly scarce insect pollinators [16]. It should be noted that flowering date is not strictly dependent on chilling requirement. Also, there were large variations in ripening date (end of July to end of September) between the studied genotypes.

In most genotypes, the flower buds were mainly on spurs, whereas distribution was mixed in some genotypes, in agreement with findings of Zeinalabedini et al. [11] and Colic et al. [15]. The dominance of genotypes with light pink petal color was observed, while some of them had white flowers. Most of the genotypes had intermediate flower size. In terms of bloom density, the genotypes were classified into four categories with most having high density. Oblong nut shape, intermediate shell color intensity, intermediate marking of the outer shell, and semi-hard shell were observed in most genotypes. Slightly wrinkled kernel shriveling was dominant and agreed with results of Zeinalabedini et al. [11] and Colic et al. [15]. Kernel pubescence was low in most genotypes. Kernel taste was predominantly sweet. One genotype showed a high percentage of double kernels (MSh35).

Nut weight varied from 1.28 to $9.23 \mathrm{~g}$. Colic et al. [15] reported nut weight with a range of 2.53 to $6.00 \mathrm{~g}$ for almond. In the present study, kernel weight ranged between 0.46 and 2.28 g. Zeinalabedini et al. [11] recorded kernel weight from 
Table II. Agronomic and important fruit traits for superior almond genotypes in this investigation.

\begin{tabular}{|c|c|c|c|c|c|c|c|}
\hline Genotype & $\begin{array}{l}\text { Flowering } \\
\text { data }\end{array}$ & $\begin{array}{l}\text { Nut weight } \\
(\mathrm{g})\end{array}$ & $\begin{array}{l}\text { Kernel weight } \\
(\mathrm{g})\end{array}$ & $\begin{array}{c}\text { Kernel weight/ } \\
\text { Nut weight (ratio) }\end{array}$ & $\begin{array}{l}\text { Double } \\
\text { kernels }\end{array}$ & $\begin{array}{l}\text { Ease of } \\
\text { hulling }\end{array}$ & $\begin{array}{l}\text { Shell } \\
\text { hardness }\end{array}$ \\
\hline MSh2 & Middle-late & 4.48 & 1.88 & 0.42 & No & Easy & Soft \\
\hline MSh9* & Late to very-late & 3.21 & 1.10 & 0.34 & No & Easy & Moderate \\
\hline MSh11 & Late & 6.35 & 2.28 & 0.36 & No & Moderate & Moderate \\
\hline MSh20 & Late & 5.18 & 1.76 & 0.34 & No & Easy & Moderate \\
\hline MSh24 & Late & 4.41 & 1.60 & 0.36 & No & Moderate & Moderate \\
\hline MSh25 & Middle-late & 6.35 & 1.55 & 0.24 & No & Easy & Hard \\
\hline MSh45 & Late & 5.63 & 1.51 & 0.27 & No & Hard & Hard \\
\hline MSh87 & Middle-late & 4.30 & 1.53 & 0.36 & No & Easy & Hard \\
\hline MSh92 & Late & 1.66 & 1.55 & 0.93 & No & Moderate & Soft \\
\hline MSh97 & Middle-late & 9.23 & 2.26 & 0.24 & No & Easy & Hard \\
\hline MSh100 & Middle-late & 4.73 & 1.78 & 0.38 & No & Moderate & Moderate \\
\hline MSh104 & Middle-late & 3.11 & 1.63 & 0.52 & No & Moderate & Soft \\
\hline Msh110* & Very-late & 3.53 & 1.21 & 0.34 & No & Easy & Hard \\
\hline MSh126 & Late & 3.40 & 2.03 & 0.60 & No & Moderate & Soft \\
\hline MSh133 & Late & 1.56 & 1.51 & 0.97 & No & Moderate & Soft \\
\hline MSh153 & Late & 5.60 & 1.58 & 0.28 & No & Easy & Hard \\
\hline
\end{tabular}

* These two genotypes were considered especially for flowering date.

0.50 to $2.30 \mathrm{~g}$, while Colic et al. [15] recorded 0.62 to $1.29 \mathrm{~g}$ for this trait.

Determining relationships between various traits can help breeders set goals for parental partner selection and breeding [10]. Strong correlations were observed between many of the studied traits (table III). Tree canopy was correlated with tree height, tree vigour, growth habit, branching habit and leaf density which corresponds with results obtained by others $[10,12,17]$. The existence of close correlations between leaf density and canopy size indicates that more leaves lead to stronger aerial growth. This correlation could be considered as a relevant relationship for selecting vigorous rootstocks suitable for dry environments where strong growth is needed at the beginning of the seasonal life cycle to induce and maintain appropriate vigour in scion, and also for reaching to an appropriate size for budding and/or grafting as soon as possible in nurseries [12]. The flowering date was highly and positively correlated with nut and kernel weights, in agreement with findings of Zeinalabedini et al. [11]. This could be interpreted as the tendency of late-season cultivars to have heavier and well-filled nuts and kernels. Furthermore, a positive correlation was observed between nut weight and kernel weight $(r=0.60)$ which is in accordance with the findings of others $[10,11,17,18]$. On the basis of the strong positive correlations among nut and kernel traits, it could be concluded that these characters have an equal effect on determining cultivar cropping potential. In addition, shell hardness was negatively correlated with nut weight $(r=-0.63)$ which is in agreement with former results $[11,19]$.

A strong negative correlation was observed between shell hardness and the kernel-to-shell weight ratio, agreeing with findings of Zeinalabedini et al. [11]. This result indicates that soft-shell cultivars have a tendency to bear larger kernels (with more kernel than shell). Also, kernel pubescence showed a high positive correlation with wrinkled kernel shriveling $(r=0.50)$ and a moderate correlation with shell hardness $(r=0.17)$. A close relationship between traits could facilitate or hinder gene introgression since strong selection for a desirable trait, could favor the presence of another desirable trait from this population [11].

Principal component analysis (PCA) was used to identify the most significant traits in the data set. The aim of PCA is to reduce the number of traits used to discriminate genotypes [12]. Previously, PCA has been used to establish genetic relationships among cultivars and genotypes, to study correlations among tree traits and to evaluate germplasm of different Prunus species [10,20-24]. Factor loading values greater than 0.65 were regarded as significant. Thus, PCA put all the traits into 14 components which explained $71.85 \%$ of total variation. The first three components explained $29 \%$ of the total variability observed (table IV). The first component, which accounted for $11.11 \%$ of total variation, featured nut weight, kernel weight/nut weight, nut weight/fruit weight, suture opening of the shell, ease of hulling, and shell hardness. The second component, which explained $9.71 \%$ of total variation, included kernel weight, fruit weight, fruit size, nut size and kernel size. Zeinalabedini et al. [11] reported that nut and kernel weights had the highest loadings in the first two components. Furthermore, Lansari et al. [25], who used a similar analysis to compare kernel, nut, and leaf characters in different almond collections, found that the variables contributing to nut and kernel size were more important than leaf traits. This indicates that these traits are not only useful for assessment of diversity but also for characterization of almond germplasm. The third component, featuring $8.18 \%$ of total variation, included tree characters (tree canopy, tree height, and tree vigour) with the highest factor loadings. This contrasts with the findings of Nikoumanesh et al. [12] who found that the most important discriminating characters for their almond germplasm were characteristics related to leaf and tree. The remaining components (PC4-PC14) explained less variability $(42.85 \%$ of total variance) and included other variables. On the other hand, seven traits including fruit shape, fruit pubescence, shell color intensity, growth habit, leaf density, leaf serration shape and location of flower buds showed low variation among the studied genotypes and were not placed in PCs. 


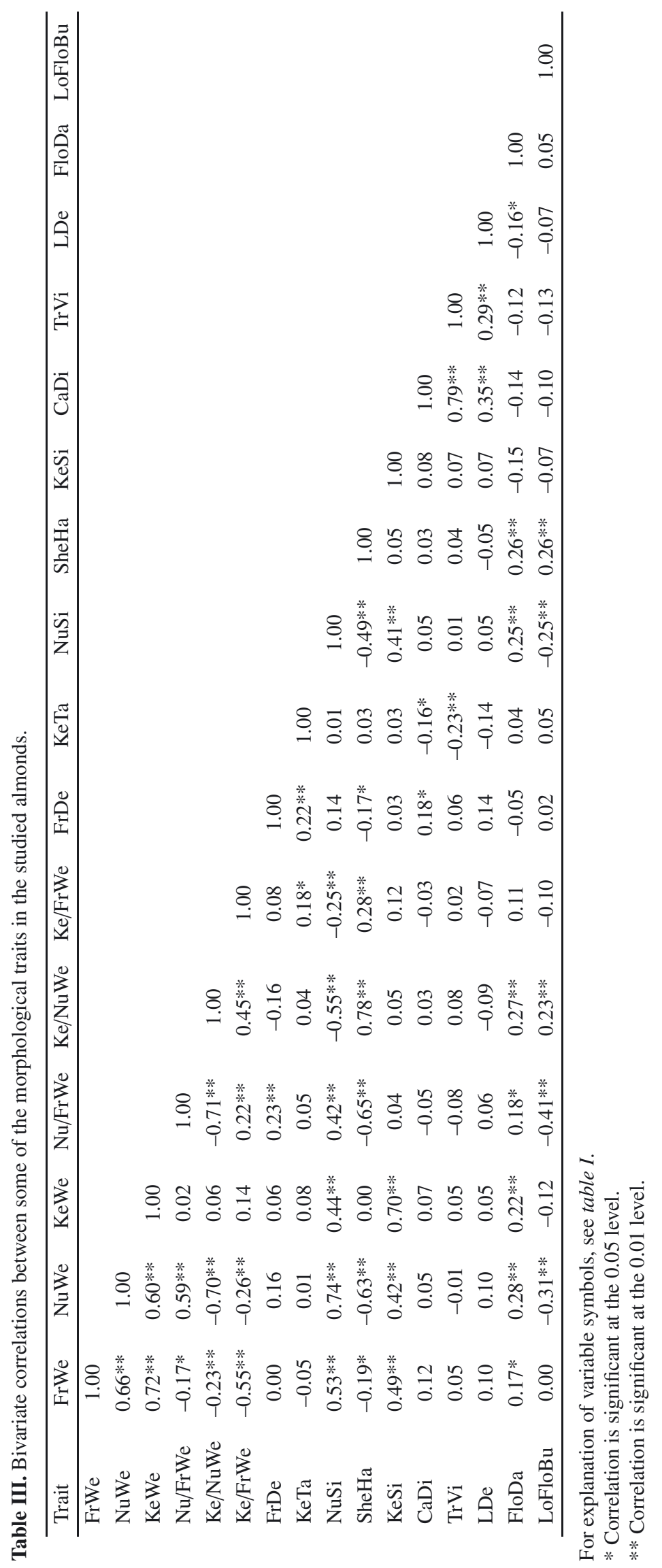




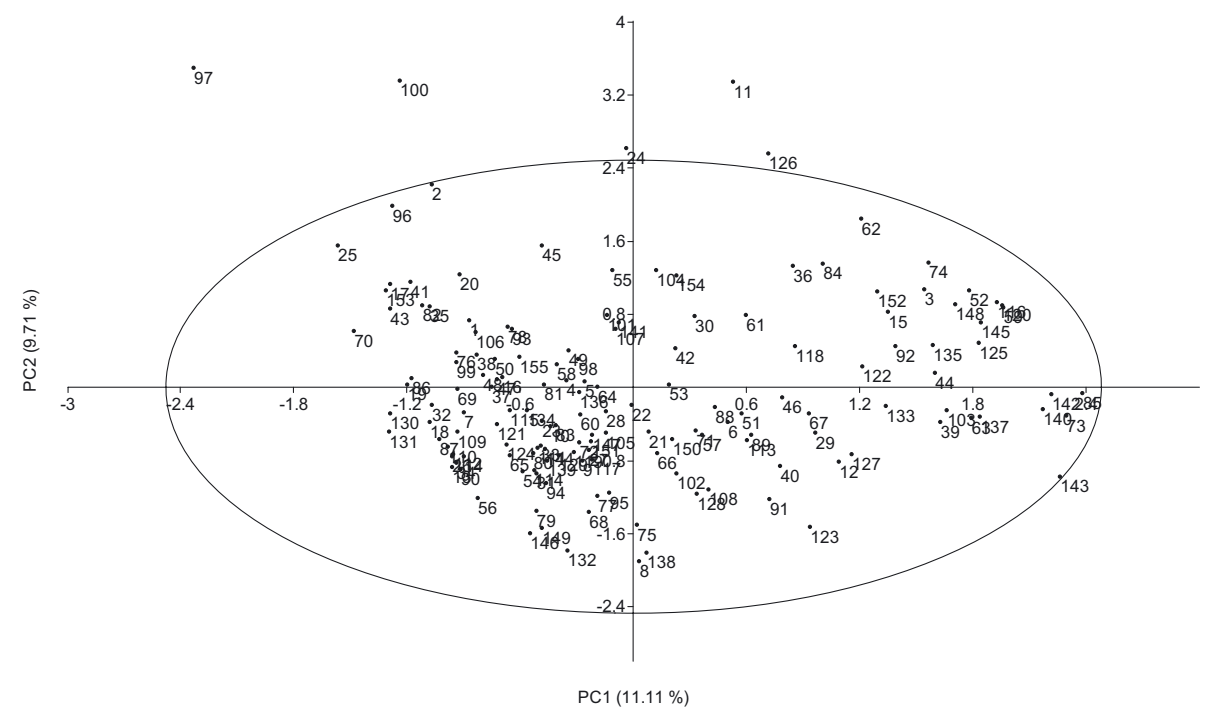

Figure 1. Factor scores of the first two principle components (PCs) for the studied almonds. Numbers in the plot represent genotypes.

Table IV. Eigenvalues and proportion of total variability for the first three principal components (PC1/PC2/PC3) in the studied almond genotypes.

\begin{tabular}{lccc}
\hline & \multicolumn{3}{c}{ Component } \\
\hline Trait & 1 & 2 & 3 \\
\hline Fruit weight & -0.09 & $0.79^{* *}$ & 0.08 \\
Nut weight & $-0.66^{* *}$ & 0.64 & 0.02 \\
Kernel weight & 0.04 & $0.88^{* *}$ & 0.04 \\
Nut weight/Fruit weight & $-0.82^{* *}$ & 0.00 & -0.05 \\
Kernel weight/Nut weight & $0.91^{* *}$ & -0.07 & 0.05 \\
Fruit size & -0.02 & $0.68^{* *}$ & 0.13 \\
Suture opening of the shell & $0.74^{* *}$ & 0.08 & -0.12 \\
Ease of hulling & $0.68^{* *}$ & 0.04 & 0.00 \\
Nut size & -0.55 & $0.60^{* *}$ & 0.02 \\
Shell hardness & $0.83^{* *}$ & -0.06 & 0.04 \\
Kernel size & 0.05 & $0.81^{* *}$ & 0.02 \\
Canopy diameter & 0.01 & 0.06 & $0.91 * *$ \\
Tree height & 0.00 & 0.04 & $0.86^{* *}$ \\
Tree vigour & 0.07 & 0.02 & $0.83^{* *}$ \\
Eigenvalue & 4.56 & 3.98 & 3.35 \\
\% of Variance & 11.11 & 9.71 & 8.18 \\
Cumulative \% & 11.11 & 20.82 & 29.00 \\
\hline
\end{tabular}

** Eigenvalues are significant.

Hierarchical UPGMA cluster analysis allowed the assessment of similarity or dissimilarity and clarified some intraspecific relationships in the studied almond germplasm. A dendrogram was produced with four clusters. The first cluster included most genotypes (146 genotypes). This cluster was divided into nine subclusters, so that genotypes showed variation. The second cluster consists of one genotype (MSh85) and the third cluster contained four genotypes (MSh11, MSh24, MSh62 and MSh126). Also, four genotypes (MSh70, MSh96, MSh97 and MSh100) were placed in the fourth cluster and showed the highest differences from other genotypes.

The scatter plot shows the distribution of almond genotypes on the PC1 and PC2 plots and the geometrical distances among genotypes that reflect their relationship in terms of phenotypic resemblance and morphological characteristics (figure 1). Most of genotypes (149 genotypes) were placed into group A. Group B consists of three genotypes (MSh11, MSh24 and MSh126). The two genotypes (MSh97 and MSh100) are in group C and MSh143 into group D.

Proceeding from positive to negative values of PC1, genotypes were characterized by lower shell hardness and lower nut weight. Genotypes MSh73, MSh146, MSh142, MSh143 and MSh85, with a high negative value on PC1, had the lowest shell hardness, the smallest nut $(1.28-1.61 \mathrm{~g})$ and the highest splinting in shell.

Proceeding from negative to positive values of PC2, almond genotypes showed a general increase in fruit, nut and kernel weight and size. Genotypes MSh11, MSh100, MSh97, MSh24 and MSh126 had the most positive values on PC2 due to their large nuts and kernels. The nut and kernel weights for genotype MSh97 were 9.23 and $2.26 \mathrm{~g}$, and 6.35 and $2.28 \mathrm{~g}$ for MSh11 genotype which represented the maximum values for these two characters. According to their position on the scatter plot (figure 1), those almond genotypes with high PC2 scores could be good progenitors for increasing nut and kernel size. On the other hand, they can be considered unique and the most promising for breeding or commercial growing. Also, genotypes MSh100 and MSh97 were middle-late-flowering; while genotypes MSh11, MSh24 and MSh126 were late-flowering, thus likely to avoid spring frosts.

Almond cultivation in Iran has a long historical background and through cross pollination there are many genotypes growing in different regions of the country. These genotypes encompass a vast diversity in many characteristics such as bloom time. Almonds are among the most heterozygous fruit crops, and encompass a wide range of socio-economic benefits from nutritional to ecological ones [1]. For conservation, management, and utilization of plant materials in genebanks, information about the diversity of germplasm collections is of great importance. The success of any breeding program is highly dependent on the extent of diversity and knowledge of the behavior of desirable traits through crosses [19]. To consider 
these facts, in this study we used 42 morphological traits to evaluate variation in 155 almond genotypes at phenotypic levels. Our results showed that nut and kernel traits are suitable for characterization of almond germplasm and could appropriately separate our samples into distinct morphological groups. Corresponding with our findings, other authors $[10,11,17,18]$ showed morphological evaluation to be an efficient tool for characterization of almond germplasm and for species distinction. Moreover, in a recent study on sour cherry variability [24], fruit characteristics could clearly discriminate among samples.

\section{Conclusions}

The knowledge of floral biology, leaf properties and fruit attributes of the genotypes studied here could be useful to choose the appropriate ones to be grown under different climatic conditions or used as parents in future breeding programs. Genotypes MSh11, MSh100, MSh97, MSh24 and MSh126 were superior in terms of consistent high fruit set percentages, large nut, large kernel, and low percentage of double kernel and can be singled out for cultivation. Furthermore, genotypes MSh9 and MSh110 were very-late flowering and could be useful as a parent to improve flowering season of cultivars.

\section{References}

[1] Kester D.E., Gradziel T.M., Almonds. In: Janick J, Moore JN (Eds) Fruit breeding, Vol III: Nuts. John Wiley and Sons, New York, 1996, pp. 1-96.

[2] Duke J.A., Handbook of nuts, CRC Press, Inc., FL., 2000.

[3] Socias i Company R., La taxonomie de l'amandier, Cahiers, Options Mediterr. 33 (1998) 91-93.

[4] Ma R.C., Yong X., Yan M., Hua X., Yuan-Qing J., Ming Qing C., Chun-Hui G., Xue-Shi H., Yo-Xiang L., Jian-Ting L., Tian Xi Z., Molecular analysis of almond germplasm in China, Options Mediterr 63 (2003) 281-290.

[5] Martinez-Gomez P., Arulsekar S., Pother D., Gradziel T.M., Relationships among peach and almond and related species as detected by SSR markers, J. Am. Soc. Hort. Sci. 128 (2003) 667-671.

[6] Dangl G.S., Yang J., Golino D.A., Gradziel T., A practical method for almond cultivar identification and parental analysis using simple sequence repeat markers, Euphytica 168 (2009) 41-48.

[7] Brown A.H.D., The core collection at the crossroads, in: Hodgkin T, Brown AHD, van Hintum TJL, Morales EAV (Eds), Core collections of plant genetic resources, Wiley, Chichester, 1995.

[8] Van Hintum T.J.L., Brown A.H.D., Spillane C., Hodgkin T., Core collections of plant genetic resources, IPGRI Technical Bulletin No. 3, International Plant Genetic Resources Institute, Rome, Italy, 2000.

[9] Odong T.L., van Heerwaarden J., Jansen J., van Hintum T.J.L., van Eeuwijk F.A., Determination of genetic structure of germplasm collections: are traditional hierarchical clustering methods appropriate for molecular marker data?, Theor. Appl. Genet. 123 (2011) 195-205.

[10] Sorkheh K., Shiran B., Rouhi V., Asadi E., Jahanbazi H., Moradi H., Gradziel T.M., Martinez-Gómez P., Phenotypic diversity within native Iranian almond (Prunus spp.) species and their breeding potential, Genet. Resour. Crop Evol. 56 (2009) 947-961.

[11] Zeinalabedini M., Sohrabi S., Nikoumanesh K., Imani A., Mardi M., Phenotypic and molecular variability and genetic structure of Iranian almond cultivars, Plant Syst. Evol. 298 (2012) 1917-1929.

[12] Nikoumanesh K., Ebadi A., Zeinalabedini M., Gogorcena Y., Morphological and molecular variability in some Iranian almond genotypes and related Prunus species and their potentials for rootstock breeding, Sci. Hortic. 129 (2011) 108-118.

[13] Gulcan R., Descriptor list for almond (Prunus amygdalus), International Board for Plant Genetic Resources, Rome, 1985.

[14] Hammer Ø., Harper D.A.T., Ryan P.D., PAST: paleontological statistics software package for education and data analysis, Palaeontologia Electronica 4 (2001) 9, available at: http:// palaeoelectronica.org/2001_1/past/issue1_01.htm.

[15] Colic S., Rakojac V., Zec G., Nikolic D., Aksic M.F., Morphological and biochemical evaluation of selected almond [Prunus dulcis (Mill.) D.A. Webb] genotypes in northern Serbia, Turk. J. Agric. For. 36 (2012) 429-438.

[16] Rickter A.A., L'amandier, Académie des Sciences Agricoles, Jardin Botanique de Nikits, Yalta 1972.

[17] Talhouk S.N., Lubani R.T., Baalbaki R., Zurayk R., Al Khatib A., Parmaksizian L., Jaradat A.A., Phenotypic diversity and morphological characterization of Amygdalus species in Lebanon, Genet. Resour. Crop Evol. 47 (2000) 93-104.

[18] Ledbetter C.A., Shonnard C.B., Evaluation of selected almond (Prunus dulcis (Miller) D.A. Webb) germplasm for several shell and kernel characteristics, Fruit Var. J. 46 (1992) 79-82.

[19] Sanchez-Perez R., Ortega E., Duval H., Martınez-Gomez P., Dicenta F., Inheritance and relationships of important agronomic traits in almond, Euphytica 93 (2007) 39-44.

[20] Ruiz D., Egea J., Phenotypic diversity and relationships of fruit quality traits in apricot (Prunus armeniaca L.) germplasm, Euphytica 163 (2008) 143-158.

[21] Nikolic D., Rakonjac V., Milatovic D., Fotiric M., Multivariate analysis of vineyard peach [Prunus persica (L.) Batsch.] germplasm collection, Euphytica 171 (2010) 227-234.

[22] Rakonjac V., Fotiric Aksic M., Nikolic D., Milatovic D., Colic S., Morphological characterization of 'Oblacinska' sour cherry by multivariate analysis, Sci. Hortic. 125 (2010) 679-684.

[23] Khadivi-Khub A., Zamani Z., Fatahi M.R., Multivariate analysis of Prunus subgen. Cerasus germplasm in Iran using morphological variables, Genet. Resour. Crop Evol. 59 (2012) 909-926.

[24] Khadivi-Khub A., Jafari H.R., Zamani Z., Phenotypic and genotypic variation in Iranian sour and duke cherries, Trees 27 (2013) 1455-1466.

[25] Lansari A., Lezzoni A.F., Kester D.E., Morphological variation within collections of Moroccan almond clones and Mediterranean and North American cultivars, Euphytica 78 (1994) 27-41. 